\title{
Importation of drugs into the United States from Canada
}

\author{
Nigel S.B. Rawson PhD, Louise Binder LLD
}

- Cite as: CMAJ 2017 June 19;189:E817-8. doi: 10.1503/cmaj.170372

$\because$ anadian physicians and their patients are all too familiar with prescription drug shortages. The production stoppage in 2012 at the facility that produces most of the generic injectable drugs in Canada became a major issue for the health care system and showed the supply chain's vulnerability. This stoppage also contributed to the establishment of a Health Canada database to provide information about drug shortages, ${ }^{1}$ which have steadily increased. ${ }^{2}$

Legislation (i.e., Affordable and Safe Prescription Drug Importation Act) that has been proposed in the United States by Senate and Congress members would allow American wholesalers, pharmacies and individuals to import qualifying prescription drugs from licensed Canadian sellers, which could accelerate drug shortages in Canada. ${ }^{3}$

The bill was introduced because drug prices in the US are much higher than in other comparable countries, because there are no regulations for price controls. This has led to many Americans not being able to afford the prescription drugs that they need. For example, an analysis of data from a comparison of drug prices in Canada and New York in 2016 reported that 45 million Americans - about $18 \%$ of the adult population - did not fill a prescription because of cost. ${ }^{4}$

A substantial proportion of Americans already purchase lowercost prescription drugs from other countries, even though the practice is illegal and imported drugs are subject to confiscation. ${ }^{5}$ A random sample survey of American adults in 2016 found that $8 \%$ of respondents said they or someone in their household had imported a drug at some point, which translates to around 19 million individuals and may underestimate the actual number. ${ }^{5}$

The importation of drugs into the US from Canada by Americans unable to afford the high prices in their own country is not new. In the early 2000s, many older adults crossed into Canada to purchase drugs at lower prices, ${ }^{6}$ and others bought cheaper drugs from Internet pharmacies that claimed to be based in Canada, although many were not. ${ }^{7}$ Concerns were raised about potential shortages and disruption in Canadian public drug insurance plans and possible safety issues resulting from drugs of indeterminate provenance being brought into Canada to supply Americans.

To avoid recreating the unregulated circumstances that occurred in the early 2000s, the Affordable and Safe Prescription

\section{KEY POINTS}

- Prescription drug shortages are frequent in the Canadian health care system.

- In an attempt to cope with unaffordable drug costs, legislation has been proposed in the United States to allow the importation of prescription drugs from Canada, which has the potential to worsen shortages in Canada.

- Canada's drug supply is not a solution to America's homegrown drug-pricing problem.

- Politicians in the US should address the issue of unaffordable drug access directly.

Drug Importation Act includes conditions that would only allow products with the same active ingredient, route of administration and strength as drugs approved in the US to be purchased from a Canadian seller certified by the US Food and Drug Administration (FDA). ${ }^{3}$ Certified sellers would be Canadian wholesale distributors or licensed pharmacies engaged in the distribution of prescription drugs for importation under the legislation, have been in business for at least five years and have a purpose other than the export program. Sellers would need to receive a valid prescription before supplying drugs to individuals. They would also have to certify that their physical premises, data-reporting procedures and licences are in compliance with all applicable Canadian laws and regulations, and have policies to monitor compliance. Sellers would have to pay a fee to fund the administration and enforcement of the program.

Access to lower-price drugs would improve the well-being of Americans without health insurance. However, the act is an impractical way to address the drug-pricing problem in the US for several reasons. First and foremost, drug manufacturers allot sales to a country by assessing the number of people who will take the drug each year based on past practice and a reasonable estimate of likely increases. Manufacturers are unlikely to increase manufacturing capacity in Canada or to allocate more drugs to Canada from other countries when they know that the drugs will be redistributed to another market, especially a much larger and more lucrative one. 
Second, although Health Canada and the FDA have relatively similar processes for drug approvals, apply the same standards and sometimes accept each other's data, their processes are not identical. Drugs can be approved for different indications or dosages. For example, olaparib received FDA approval in patients with BRCA-mutated advanced ovarian cancer who have had three or more previous lines of chemotherapy, whereas Health Canada approved the drug for patients with platinum-sensitive relapsed $B R C A$-mutated high-grade serous epithelial ovarian, fallopian tube or primary peritoneal cancer that responds to platinum-based chemotherapy. The differences frequently reflect varying views on the risks of specific products. Drugs are also commonly submitted for and receive regulatory approval later in Canada than in the US; ${ }^{8}$ olaparib was approved by Health Canada more than 16 months after receiving FDA approval.

Third, the FDA lacks the resources needed to oversee a major importation program, as recently stated by four former FDA commissioners in a March 2017 letter to Congress. ${ }^{9}$ Without a large increase in resources, the FDA would not be able to certify each seller's credentials under the act, which implies that the program would rely on self-certification. Adequate certification of sellers is crucial ${ }^{10}$ because, as the former commissioners highlighted, ineffective accreditation may lead to "substandard, unsafe, adulterated or false" drugs being purchased by Americans. ${ }^{9}$

The actions of Bernie Sanders, who has led the proposal, President Trump and others may simply be a way of putting pressure on the US to introduce controls for drug pricing or for pharmaceutical companies to make their products more affordable. However, if it is enacted and Canadian wholesalers and pharmacies attempt to supply even a small number of Americans who are currently unable to pay for their drugs, shortages would increase in Canada and cause substantial distress to Canadians. Canada's drug supply is not a long-term solution to America's homegrown drug-pricing problem.

Canada has a system, albeit a criticized one, for assessing drug values and controlling prices within its public drug plans. Trying to access part of Canada's overall health care system out of context is not appropriate. The Affordable and Safe Prescription Drug Importation Act may sound reasonable, but it is a band-aid approach to a deeper problem. Politicians in the US should directly address the issue of how to achieve affordable drug access and not disrupt another country's health care system in an attempt to solve the problem.

\section{References}

1. Drug shortages Canada. Ottawa: Health Canada; 2017. Available: https://www. drugshortagescanada.ca (accessed 2017 May 8).

2. Owens B. Drugs are going missing, but why? CMAJ 2016;188:716-7.

3. Affordable and Safe Prescription Drug Importation Act introduced to help lower skyrocketing cost of medicine. Washington (DC): Bernie Sanders [website], 2017 Feb. 28. Available: https://www.sanders.senate.gov/newsroom/press-releases/ affordable-and-safe-prescription-drug-importation-act-introduced-to-help-lower -skyrocketing-cost-of-medicine (accessed 2017 May 8).

4. Bluth R. Trump's promise to rein in drug prices could open floodgate to importation laws. Kaiser Health News 2017 Mar. 22. Available: http://khn.org/news/ trumps-promise-to-rein-in-drug-prices-could-open-dam-to-importation-laws (accessed 2017 May 8).

5. Bluth R. Faced with unaffordable drug prices, tens of millions buy medicines outside U.S. Kaiser Health News 2016 Dec. 20. Available: http://khn.org/news /faced-with-unaffordable-drug-prices-tens-of-millions-buy-medicine-outside -u-s (accessed 2017 May 8).

6. Korcok M. Cheap prescription drugs creating new brand of US tourist in Canada, Mexico. CMAJ 2000;162:1869-70.

7. Zuger A. Rx: Canadian drugs. N Engl J Med 2003;349:2188-90.

8. Rawson NSB. New drug approval times and safety warnings in the United States and Canada, 1992-2011. J Popul Ther Clin Pharmacol 2013;20:e67-81.

9. Califf RM, Hamburg MB, McClellan MB, et al. Letter to Congress; 2017 Mar. 22. Available: https://www.documentcloud.org/documents/3519007-FDA-Commissioners -Drug-Reimportation.html?utm_source=newsletter\&utm_medium=email\&utm _campaign=newsletter_axiosvitals (accessed 2017 May 8).

10. Bate R, Jin GZ, Mathur A. In whom we trust: the role of certification agencies in online drug markets. BE J Econ Anal Policy 2014;14:111-50.

Competing interests: Nigel Rawson has received consultant fees from IMS Brogan, United Biosource Corporation, Novartis Pharmaceuticals Canada, Janssen Canada and Advocacy Solutions/Cohn \& Wolfe. He has also received research and publication fees from Canadian Health Policy Institute, Fraser Institute and Ward Health; honoraria and compensation for travel from La Fondation Devenir; and compensation for publication processing expenses from BIOTECanada. No other competing interests were declared.

This article has been peer reviewed.

Affiliations: Eastlake Research Group (Rawson), Oakville, Ont.; Canadian Health Policy Institute (Rawson), Toronto, Ont.; Save Your Skin Foundation (Binder), Vancouver, BC

Contributors: Nigel Rawson and Louise Binder both contributed substantially to the conception of the work, drafted the article, reviewed it critically for important intellectual content, gave final approval of the version to be published and agreed to be accountable for all aspects of the work.

Correspondence to: Nigel Rawson, EastlakeRG@gmail.com 